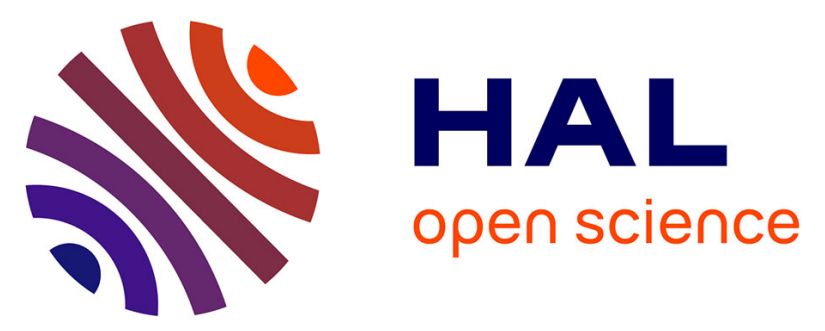

\title{
CONTEXT MANAGEMENT IN COLLABORATIVE DECISION MAKING IN COMPLEX DESIGN PROJECTS
}

\author{
Marija Jankovic, Julie Stal-Le Cardinal, Jean-Claude Bocquet
}

\section{To cite this version:}

Marija Jankovic, Julie Stal-Le Cardinal, Jean-Claude Bocquet. CONTEXT MANAGEMENT IN COLLABORATIVE DECISION MAKING IN COMPLEX DESIGN PROJECTS. International Journal of Product Development, 2014, 20 (4), pp.286-303. 10.1504/IJPD.2015.071397 . hal-01216806

\section{HAL Id: hal-01216806 \\ https://hal.science/hal-01216806}

Submitted on 17 Oct 2015

HAL is a multi-disciplinary open access archive for the deposit and dissemination of scientific research documents, whether they are published or not. The documents may come from teaching and research institutions in France or abroad, or from public or private research centers.
L'archive ouverte pluridisciplinaire HAL, est destinée au dépôt et à la diffusion de documents scientifiques de niveau recherche, publiés ou non, émanant des établissements d'enseignement et de recherche français ou étrangers, des laboratoires publics ou privés. 


\section{CONTEXT MANAGEMENT IN COLLABORATIVE DECISION MAKING IN COMPLEX DESIGN PROJECTS}

Marija Jankovic, Dr., Assistant professor

Corresponding author,

Ecole Centrale Paris, Industrial Engineering,

Grande Voie des Vignes, 92295 Chatenay-Malabry, France,

E-mail: marija.jankovic@ecp.fr,

Phone: +33 1411314 27, Fax : + 33 (01) 41131272

Phone: + 33 (06) 23684150

Julie Stal Le Cardinal, Dr., Professor

Ecole Centrale Paris, Industrial Engineering,

Address: Grande Voie des Vignes, 92295 Chatenay-Malabry, France,

E-mail: julie.stal-lecardinal @ecp.fr,

Phone: + 33 (01) 411315 69, Fax : + 33 (01) 41131272

Jean-Claude Bocquet, Dr., Professor

Ecole Centrale Paris, Industrial Engineering,

Address: Grande Voie des Vignes, 92295 Chatenay-Malabry, France,

E-mail: jean-claude.bocquet@ecp.fr,

Phone: + 33 (01) 411316 06, Fax : + 33 (01) 41131272 
Abstract

The notion of context seems to be a growing subject in the engineering sciences. Several studies have pointed out the necessity to address the contextual limitations in collaborative design projects. It has been identified as one of the major factors that contribute to inadequate knowledge reuse in design projects. Nevertheless, the definition of the context depends on the subject and the field of application. In this paper, we point out different definitions of the context in artificial intelligence, engineering and cognitive sciences. In this research study we present a proposition for context modelling representing only one part of collaborative decision-making support. The research study presented in this paper is a result of collaboration with one of the French car manufacturers. Within the conceptual model of collaborative decision-making, we propose to integrate the information concerning three different contexts: decision, project and enterprise context. The aim of this model is to help and support the project team in project management.

Keywords: context modelling, collaborative decision-making, new product development, early stages

\section{INTRODUCTION}

Several studies have shown that the notion of the context is a growing issue as well as strong dependency between the design and new product development activities and their context (Culley \& McMahon, 2006; Gonzalez et al., 2011; Longueville \& Gardoni, 2003). (Fruchter et al., 2007) also address this issue of contextual limitations as a major limitation for collaborative design projects. They pointed out the necessity for designer to gain more insight on context within which the decisions were made. The study also pointed out that in order to be able to reuse knowledge, the decision makers should be able to access this context and interact with it. The definition of the context and developed modelling approaches are numerous and can be very different.

The object of our research work concerns the collaborative decision-making in New Product and Process Development (NPPD) and more particularly the early stages of NPPD. There has been a considerable body of work concerning the definition of the context in artificial intelligence, engineering design and cognitive sciences. Nevertheless, the concept of context still seems not defined in the design process of complex systems. In order to develop an adequate tool for project team support in NPPD, we have developed a conceptual model of collaborative decision-making. Within this model, we propose a context ontology integrating three different contexts influencing the 
collaborative decision-making process. This work was realised in collaboration with one of the French automotive constructers and benefits from interesting data gathered on 7 vehicle design projects. Moreover, after 3 months of use of the proposed tool, some interesting feedback from 3 new vehicle design projects was gathered highlighting the need to pursue to better defining and understanding design context.

Therefore, we propose a following organisation of this paper. First part of the paper concerns different approaches, definitions and representation of the context. The second part exposes the Project Definition Phase, early stage of vehicle design, its characteristics and issues that designers are confronted with as well as the specificities of collaborative decision-making in this phase. In the third part, we propose the integration of three different embedded contexts that were evaluated important to define: the decision, project and environment context. In the end, we present our conclusions and research perspectives.

\section{CONTEXT DEFINITION AND RELATED ISSUES}

\subsection{WHY DO WE NEED TO DEFINE THE CONTEXT?}

The importance of the context theories and context modelling in engineering design has been stated in several studies (Brézillon, 1999b; Longueville \& Gardoni, 2003). Longueville (Longueville \& Gardoni, 2003) points out the necessity to address these issues when modelling complex system design activities or when formalizing the phenomena representing the real world behaviour due to the growing complexity of design activities and change of the business environment:

- Communication and collaboration: design process needs more interaction between people, specially teams that are geographically distributed and involving design team members of different culture and organizations;

- Environment and evolution: the development of firms is highly connected to the environment and therefore the context here is directly connected to the notion model validity;

- Knowledge and information: Context here is integrated so that the designers obtain the adequate knowledge in a appropriate time in the design process; 
- "Globalization" of the design activities that implies the need for generic tools and support.

In artificial intelligence, the notion of context modelling has been a growing issue since 1991 ((Brézillon, 1999a). Brézillion (Brézillon \& Pomerol, 1996) states that the problem of inadequate capture of explicit context has been one of the major reasons for the failure of many Knowledge-Based systems. In a field of ubiquitous (Strang \& Linnhoff-Popien, 2004) computing the context-awareness is an important issue because it is thought to be a promising solution for problems implying the usage of different mobile terminals in a distributed system. Henricksen (Henricksen et al., 2002) underlines that the context is needed in pervasive computing because of its need to function is a highly dynamic environment and in order to place as few as possible demands to the user.

Furthermore, most of the authors agree upon the fact that the context is very important for the decision-making process (Brézillon, 1999b; Brézillon \& Zaraté, 2004; Longueville, 2003; Pomerol \& Brezillon, 2001). Brézillon and Zaraté (Brézillon \& Zaraté, 2004) emphasize the fact that "making one context explicit can improve in a consequential way interaction among the members of the firm".

\subsection{DEFINITION OF THE CONTEXT}

The first definitions of the context can be found in Natural Language. Frege (Frege, 1985) has already in 1892 defined three different contexts in the usage of names: ordinary, direct and indirect. The concept of context has been an object of different studies (Longueville, 2003; Longueville \& Gardoni, 2003; Pomerol \& Brezillon, 2001): linguistic, semantic, modelling, philosophy, information systems, artificial intelligence and engineering. There are several definitions depending on the research and the domain. Brézillon (Brézillon, 1999b) has already pointed out the difference in the approaches in cognitive and in engineering sciences that were explored during the two workshops on context at IJCAI-93 and IJCAI-95. "The cognitive science view is that context is used to model interactions and situations in a world of infinite breadth, and human behaviour is key in extracting a model. The engineering view is that context is useful in representing and reasoning about a restricted state space within which a problem can be solved". Nevertheless, he states that the differences in the definition of the context come from different positioning of these two scientific domains. Therefore, the both scientific domains face the same problems concerning its definition. 
However, the definition of the context seems not to be uniform and generally accepted (Brézillon, 1999a): a set of preferences and/or beliefs, a window on a screen, a list of attributes, the product of an interpretation, a collection of context schemata, paths in information retrieval, slots in object-oriented language, adaptation of the application in terms of time, location, preferences, factors that are valid in a certain situation. The field of artificial intelligence has been particularly fruitful in the research concerning the context. The main research question in this area is the relation between the knowledge and the context (Pomerol \& Brezillon, 2003) suggest that there are three types of context in the process of problem solving: proceduralised context, contextual knowledge and external knowledge. The proceduralised context is used is a context shared by those who participate in the problem solving and in this process is directly but tacitly used. The contextual knowledge concerns the context that is not directly used in the problem-solving process. The authors consider the proceduralised context as a contextual knowledge activated and structured to make diagnosis, decisions and actions. The external knowledge represents the context that has nothing to do with the current decision-making but is known by many of those involved.

Longueville (Longueville \& Gardoni, 2003) explores the question of context within the engineering studies and defines the context is "something that encircles and gives a sense to another thing". Hasher (Hasher \& Zack, 1984) gives a following definition: "The context is a collection of relevant conditions and surrounding influences that make a situation unique and comprehensible". Akman and Surav (Akman \& Surav, 1996) underline that the context is helping us to create our common understanding of a situation by selection an "appropriate meaning from a set of possible meanings". Leech (Leech, 1981) relates that "the effect of the context is to attach a certain probability to each sense (the complete ruling-out of a sense being the limiting case of nil probability".

\subsection{DIFFERENT APPROACHES TO CONTEXT MODELLING}

Context modelling depends upon the reason why we need information about a context. There are numerous approaches towards context modelling: key value models (Schilit et al., 1994), logic formalization (Akman \& Surav, 1996; McCarthy, 1993), graphical models (Henricksen et al., 2003), semantic networks (Brézillon, 1999b), object oriented models (Schmidt et al., 1999), ontology based 
models (Ozturk \& Aamodt, 1998), knowledge based models (Brézillon, 1999b; Longueville \& Gardoni, 2003). Our goal in this paper is not to be exhaustive in relating different fields and different approaches towards context modelling. For an extensive overview several survey studies of very good quality were done in recent years (Akman \& Surav, 1996; Brézillon, 1999a; Brézillon, 1999b; Strang \& Linnhoff-Popien, 2004) (Akman \& Surav 1996). In this part we will point out approaches that represent major interest for us when it comes to context modelling in engineering design activities.

One of the first definitions of the context using logic formalization is given by McCarthy in 1993 (McCarthy, 1993) and his research group at Stanford university. McCarthy in his approach does not contribute to the definition of the context but introduces context as abstract mathematical objects that can be manipulated. Therefore, the basic relationship connecting context and a proposition is defined as:

ist $(\mathrm{c}, \mathrm{p})$ : asserting that the proposition $\mathrm{p}$ is true in the context $\mathrm{c}$.

In this approach there are two properties of the context: 1) contexts are abstract objects and 2) contexts are first-class citizens and we can use them the same way me use other objects.

Guha (Guha, 1995) uses the notion of context when defining the micro theories concerning the theories of limit domains. In his approach to defining the context, it is considered to have two basic properties: 1) a set of axioms that are related to the micro theory and 2) a vocabulary giving the syntax and semantics for each predicate and each function. Giunchiglia (Giunchiglia et al., 1992) considers the context in order to encode the agent's perspective of the world and that is used in a given reasoning process. When it comes to the formalization of the previous, Giunchiglia starts out from the definition of partitioned databases (each partition $\mathrm{A}_{\mathrm{i}}$, may have a different vocabulary). The context $\mathrm{c}_{\mathrm{i}}$ is therefore a triple:

$$
\left\langle\mathrm{L}_{\mathrm{i}}, \mathrm{A}_{\mathrm{i}}, \Delta_{\mathrm{i}}>\right.
$$

where $L_{i}$ is a language of the context, $A_{i}$ is the axioms of the context and $\Delta_{I}$ is the inference mechanism to the context. 
Akman and Surav (Akman \& Surav, 1996) propose in their work Extended situation theory based upon the work of Barwise and Perry (Barwise \& Perry, 1983) and Devlin (Devlin, 1995). Situation theory is a program with the objective to develop a "unified mathematical theory of meaning and information content" (Barwise \& Perry, 1983; Surav \& Akman, 1994) in the 80' introduced the ideas constituting the context theory. The two basic concepts are infons and situations. Infons are basic information units and can be represented as:

$$
<<\mathrm{P}, \mathrm{a}_{1}, \ldots, \mathrm{a}_{\mathrm{n}}, \mathrm{i}>>
$$

where $\mathrm{P}$ is a n-place relation, $\mathrm{a}_{1}, \mathrm{a}_{\mathrm{n}}$ different objects and $\mathrm{i}$ is the polarity ( 0 or 1$)$ (meaning true or false). Situations are considered to be a structured part of the reality that one agent can manage to pick up and are denotated as $s$ support $\alpha(\mathrm{s} \mid=\alpha)$, meaning that the infon $\alpha$ is true for the situation $\mathrm{s}$. Interesting concepts within this theory are schemes of individuations, "a way of carving the world into uniformities" (Akman \& Surav, 1996). The basic types that were presented in their work were: TIM (the type of temporal location), LOC (the type of spatial location), IND (the type of an individual) and SIT (the type of the situation).

Edmonds (Edmonds, 1999) proposes the following definition of the context: "the abstraction of those elements of the circumstances in which a model is learned, that are not used explicitly in the production of an inference or prediction when the model is later applied, that allows the recognition of new circumstances where the model can be usefully applied". The definition is illustrated in the figure 1. This definition of context is linked to the possibility for knowledge transferring.

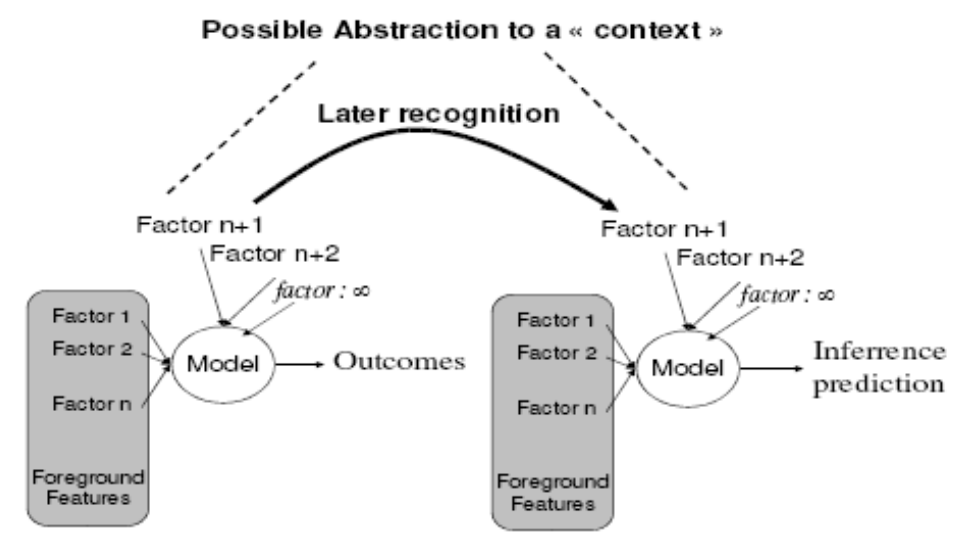


First ontology based context models were introduced by Ozturk and Aamodt (Ozturk \& Aamodt, 1998). In this work, authors are exploring the content theory of context and different interrelations between different research fields, especially cognitive psychology and artificial intelligence. Starting from the context typology proposed by Hewitt (Tiberghian, 1986) and their vision of the context as a deliberate process dependent on the role of the actor in this process, with 2 key elements of the process, actor and external situation, they propose 2 type of contexts: internal and external context (Figure 2.). The external context contains two distinct elements: those related to the target and those related to the environment.

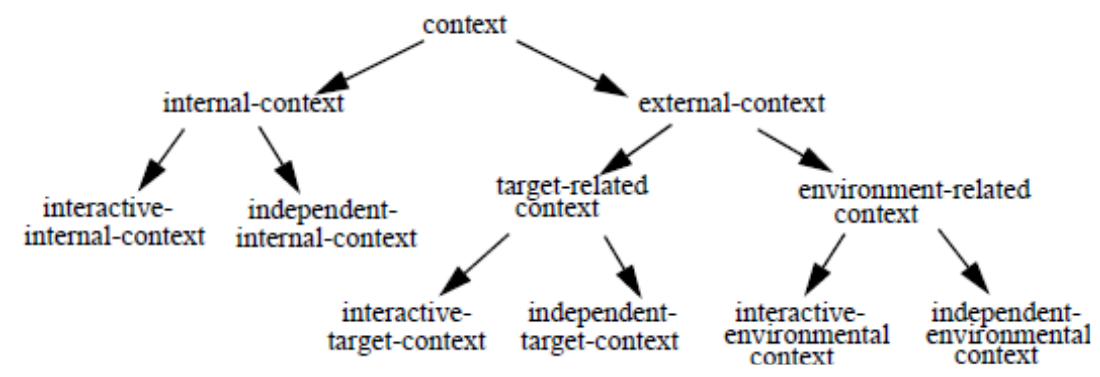

Figure 2. Context ontology based upon the role of the actor

Brézillion (Brézillon, 1999b) defines to context in view to the knowledge that should be considered in a given situation in problem solving. Author states that context is permitting to structure the knowledge bases into traceable units that are often hierarchically organized. In this approach the context contains: 1) sets of concepts (schemas, frames or structures) and 2) set of constraints used for the restriction of the manner in which the instances of the concepts are created and combined. Brézillion underlines as well the need for context manager in order to ensure the correct transfer of information from one context to another.

(Fruchter et al., 2007) propose a CoMem system in order to integrate the context in the knowledge reuse situation. Authors propose the system that supports designer into browsing large corporate archives; explore projects context and evolution history of these items. In order to enhance the usability of this system, authors have implemented a squarified treemap algorithm to display a hierarchical organised corporate knowledge. As for the context modelling, the CoMem project context 
explorer uses fisheye formulation to assign the degree of interest of any item selected for overview. This helps identify documents that constitute the project context and reuse of knowledge, but it does not necessarily contribute to the understanding of factors that constitute the context supporting the decision making.

Gonzales (Gonzalez et al., 2011) utilizes a context-based reasoning in order to develop situation awareness agents in the project management. They call it the Project Manager Agent or PM-Agent. PM-Agents are monitoring collaboration and their aim is at discovering conflicts at the earliest time. The behaviour the PM-Agent is also defined by the Context Base that is hierarchically defined with Mission Context, Major Contexts and several layers of Minor Contexts. This data is used afterwards to monitor all project management developments and signal and prevent potential conflicts.

Longueville (Longueville \& Gardoni, 2003) on the other hand adopts a more pragmatic approach defining three levels of context necessary to integrate in supporting empirical studies and descriptive modelling: explicit context, implicit context and overall context. The explicit context is possible to formalise and is represented as additional parameters of the model. The implicit context is not fully formalisable. It is a result of the learning process and can be represented partially as additional information. The overall context concerns the surrounding context that is complex and hard to recognise.

The main objective of our study is to support the project and the design team in collaborative decision making in early stages of NPPD. Collaborative decision-making implies a various number of actors with different roles and different integration in the process. Therefore, it was necessary to address the issue of context formalization when defining collaborative decision making processes. In our approach we defined context as additional constraints in the decision making process that are to be taken into account. The difficulty of context modelling in our case is the existence of different points of view and different objectives in the same process.

\section{RESEARCH DESIGN}


Car manufacturing company that initiated this research has been in particular experiencing problem with regard to the initial vehicle design stage: Project Definition Phase. The company has been experiencing time overruns (up to $25 \%$ ) that are due to the difficulty of managing design convergence in this early stage. The initial field research has underlined that this was due both to the project management methodology as well as the fact that this process is collaborative decision-making process (Jankovic et al., 2010). In the project management, after the definition of the project scope, a Work Breakdown Structure (WBS) is defined that will support definition of project activities. However, as project objectives are fuzzy in this stage it is difficult to identify WBS packages and project activities. On the other hand, this phase concerns the definition of overall vehicle design objectives. Vehicle design complexity implies that these decisions are made in a collaborative manner. The difficulty of the process is that each designer has specific and often contradictory objectives.

The global research design, following the Design Research Approach (Blessing \& Chakrabarti, 2009) was conducted in several phases: 1) Critical Literature Review and Problem Definition, 2) Data Gathering, 3) Developing collaborative decision-making model and related design project tool and 4) Implementation and utilisation by different vehicle design projects. After clearly identifying the problems concerning the collaborative decision-making, a test bed of 7 vehicle development projects in 3 vehicle development platforms has been identified to gather information pointing out relevant causal factors. The initial hypothesis of this research was that clear definition of collaborative decision-making process will support better management of vehicle convergence. Context modelling has been also pointed as an important part of decision-making processes. In order to address this issue a conceptual collaborative decision-making model highlighting critical data needed for different decisions was proposed. The model was developed using UML and the work was done in collaboration in particular with an engineer who is responsible for the vehicle design methodology support. The decision-making support tool was tested on $25 \%$ of current vehicle design projects. One part of the validation consisted in determining the relevance of the contextual parameters in collaborative decision-making. 


\section{VEHICLE DESIGN}

The Project Definition phase is one of the early stages in New Product and Process Development (NPPD). NPPD in this company can be represented as in Figure 3 (Jankovic, 2006; Jankovic et al., 2009). The Project Definition Phase begins after program definition where market segmentation and research have been made as well as Research and Development process (R\&D). Objectives of this phase are to clearly define project objectives and have the first feasibility study related to strategic orientations.

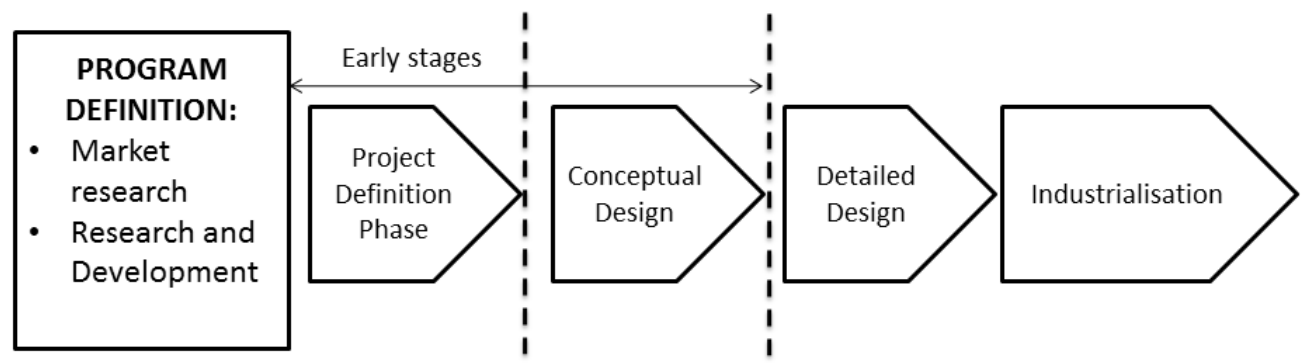

Figure 3: Company related New Product and Process Development (NPPD) Process

Collaborative decision making concerning the project and the design choices and orientations is a highly complex process due to its several characteristics:

- Complexity of the system that is designed (increasing number of parts and interrelationships);

- Different knowledge that is necessary in the design process;

- Different design objectives for project and design departments and actors;

- Different background and culture of design teams.

Early stages in NPPD process are also characterized by high uncertainties: external or environmental uncertainties and internal (product or process related). Therefore, supporting project and design team in clarifying objectives and constraints in these processes is highly influencing the success of one project and therefore company's survival on the long term.

In order to investigate causes of time overruns, a test bed of 7 vehicle development projects in 3 vehicle development platforms has been identified to gather information pointing out relevant causal 
factors. This sample of projects was chosen because it was considered to be representative, constituting a little bit over $40 \%$ of all ongoing projects at the time. The data gathering sources and process is presented in the table 1.

\begin{tabular}{|c|c|c|c|}
\hline & \multicolumn{2}{|c|}{ MARKET SEGMENTS } \\
\hline & & France & International \\
\hline \multirow{3}{*}{  } & Small Vehicles & 1 & 1 \\
\hline & Compact vehicles & 2 & 1 \\
\hline & Sedan & 2 & \\
\hline
\end{tabular}

Table 1. Data gathering sources for three vehicle platforms

Initial observations showed that at the very beginning of the Project Definition Phase, different enterprise departments give the global guidelines for the definition of project objectives to the project team. Some of these departments are: marketing, production, innovation, and strategy. The given guidelines represent the transcription of strategic orientations of the enterprise, given by different fields. The project team has also to take into account the results of market segmentation and targeting, as well as to integrate the client needs. The relationships between different objectives in the decomposition process are very complex because it is:

- Knowledge based process: it is based upon the previous experience of the project and design team members as well as company's history;

- Not easily traceable process: condensing different objectives of the higher level into project objectives is not always easy to apprehend;

- Process where a large quantity of data exchanged: the data sources are very various and of different reliability.

The process of project objectives' definition of is also a collaboration process between the enterprise departments, responsible for enterprise objectives and different knowledge poles, representing the experts in specific domains. The responsibility for the project results is project teams', but in order to do so, the project team has to create the cohesion between these two levels. Every step of this process is done in collaboration and negotiation with one or both levels. As enterprise departments have a 
strategic vision concerning one field, thus having the global overview, and the knowledge poles have more operational vision involving feasibility, different problems can arise: conflict apparition, incomprehension due to different backgrounds and language used, difference in points of view concerning the same problem, different objectives to attain.

Collaborative decision-making concerns mostly the tactical level in a company where different representatives of upper stated levels decide upon one particular problem concerning the project and its definition. Every actor in this decision-making has a specific knowledge and information of the problem. Moreover, every actor is responsible for project objectives' definition in one project field. Therefore, as these different actors have different knowledge, information and vision concerning the problem, the collaborative decision-making can be a "fat-soil" for conflict apparition.

In the scope of collaborative decision-making, the notion of context is highly important. The perception of one collaborative decision and particular problem, even though collaborative decisions are not geographically distributed, depend upon several contexts: individual (culture, knowledge, and background), group (department) and company (position and intervention in the NPPD process). These different perceptions of the same problem result in conflicts that can jeopardise the project. Therefore, the hypothesis made in this work is that making context explicit in one collaborative decision is important because it can support information sharing within the design team and elicitation of influencing factors or constraints gaining additional insight related to one collaborative decision.

\section{DIFFERENT CONTEXTS IN COLLABORATIVE DECISION MAKING}

In order to support collaborative decision-making in the early stages, we propose to integrate context modelling. Proposed model for collaborative decision-making is constituted of four different views: Objectives, Transformations, Process and Environment (Jankovic et al., 2010). In this paper we will focus on the Environment view because it is where we integrate the notion of the context. We have identified three different environments in New Product and Process Development and for each environment we propose to define factors that support collaborative decision-making:

- Decision environment: environment that concerning the decision making; 
- Project environment: concerning the project orientations and

- Enterprise environment: relating to the strategic enterprise orientations and constraints.

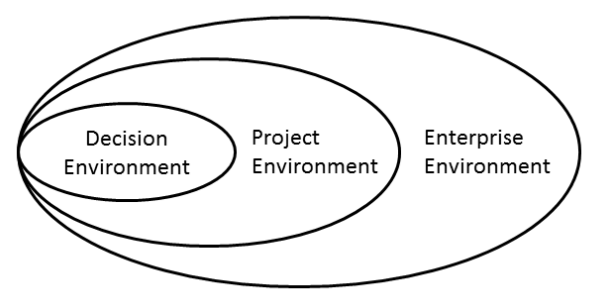

Figure 4.Three different environments influencing collaborative decision-making

Each of these environments is identified by its context and different actors relevant for collaborative decision-making. The context is defined as influencing factors or constraints that are essential in focusing the problem solving process and that are to be defined in a common effort with all actors participating in this process. Figure 4 illustrates that it is important not to see these environments as separate and distinct entities as they are interdependent and embedded. Our objective is to identify the most pertinent elements influencing the collaborative decision-making and thus essential to take into consideration while deciding.

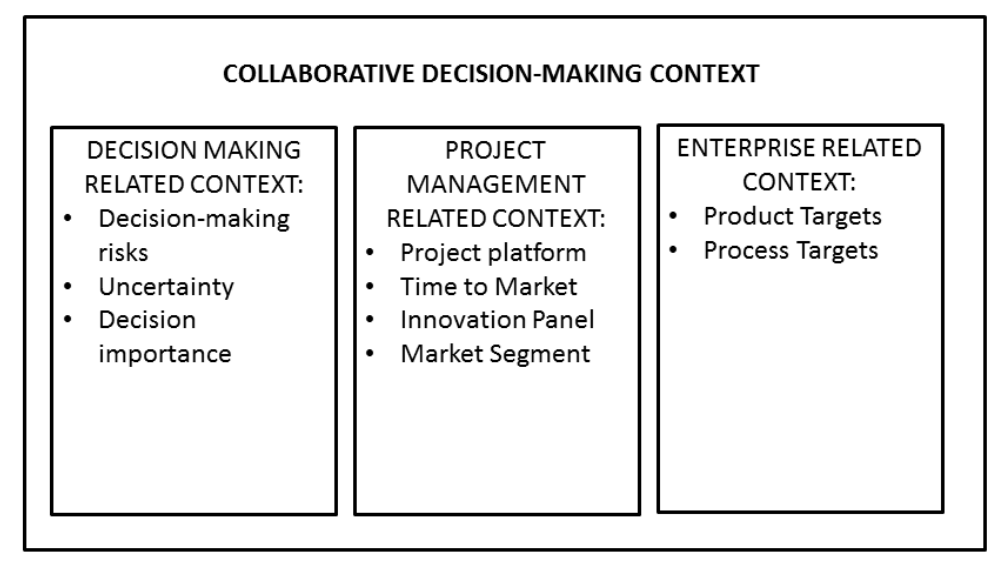

Figure 5. Proposition of collaborative decision-making context

The overall collaborative decision-making context is presented in Figure 5. For each environment associated context has been defined though a set of related influencing factors. For each collaborative decision, these 9 factors are defined and captured in order to support collaborative decision-making.

\subsection{DECISION MAKING RELATED CONTEXT}


The decision-making related context is constituted of three main influencing factors that help the project team to reduce the solution space concerning project development orientations:

- Decision-making risks: risks related to the choices made and related preventive activities;

- Uncertainties: critical information that is used as a base for decision making and expert estimation of related uncertainty to this information; and

- Decision importance: four levels related to the level of decision-makers (for example if it is the highest level that means that the decision is made by company CEO).

These factors are based upon a literature review (Aldag \& Fuller, 1993; Esser, 1998; Janis, 1971) and the confrontation of these factors with their importance in the NPPD process.

The homogenous vision concerning these three factors is important for collaborative decision-making. As collaborative decision-making is subject to different value judgments, different decision-making criteria and different decision objectives, it is necessary to "negotiate" or determine the value of these factors in view to have a better vision concerning the potential hypothesis and solution space. Definition of decision-making related context is driven by the collaborative decision-making pilot whose role is explained in the next paragraph.

\subsection{Project Management Related Context}

Project environment concerns project orientations. The project context is mostly determined by different project types. The importance of one collaborative decision will be different regarding to different project types. In this research study, we have identified the flowing influencing factors that are considered to be differentiating for the project types in this case (vehicle development projects in the early stages):

- Platform: vehicle platform that is a base for the project and the COTS (component of the shelf) targets,

- Time to Market: development time target that has been discussed and set as a target by the company,

- Innovation panel: a set of innovation that are to integrated or infused in the vehicle system, 
- Market segment: information related to the market segment as well as positioning of major vehicle competitors within the segment.

Data gathering and the definition of the values for one project concerning these variables are driven by the Project Manager, because he has the global view of the project and it is his responsibility to answer to the demands of the Steering committee for the project development.

\subsection{ENTERPRISE RELATED CONTEXT}

The Enterprise Environment refers to strategic enterprise orientations and constraints. These orientations and constraints are needed to be defined as a result of different orientations that are given to one project by different departments participating in the definition of global strategy. We have defined two types of influencing factors that define enterprise related context:

- Product enhancement: list of vehicle development targets that are a part of strategy and market differentiation like new technology development,

- Process enhancement: list of vehicle process enhancement targets that are considered as major improvements for the company like target to diminish physical interfaces that has a concrete need to reorganise engineering process.

The definition of these influencing factors and the negotiation process is driven by the Project Manager.

\section{COLLABORATIVE DECISION-MAKING TOOL}

In order to support collaborative decision-making, a tool for Project Definition Phase was proposed (Figure 6). The information related to the collaborative decision can be seen in a specific view (left side in Figure 6) containing information on decision objectives, decision-making process, related information or data; and decision-making environment. Context related data is situated in the environment part of the view. This model is a base for collaborative decision-making process represented on the right side in Figure 6. Collaborative decision-making processes are represented as decision graphs. Each node is one collaborative decision that gives access to the data related to this decision and contained in the collaborative decision view. 




Figure 6. Collaborative decision making tool (Left side: Collaborative decision view. Right side: Collaborative decision-making processes view.)

Seventy three collaborative decisions, organized into thirteen collaborative decision making process, have been modeled in the Project Definition Phase. The organization into these thirteen decision making processes has been done in discussion with project team taking into account the design domain that is influenced by the decision as well as some of organizational aspect of the company. For instance all decisions that are related to designing the manufacturing process and integrating manufacturing constraints as early as possible are organized in one collaborative decision-making process. This modelling has been done with regard to the test bed of 7 vehicle projects that were discussed previously.

\subsection{CONTEXT RELATED FACTORS}

It was decided to test the utilization of the tool on $25 \%$ of ongoing projects. The vehicle design projects are launched with 3 to 6 months of difference. For each project between 10 and 15 collaborative decisions were followed up. This represents between $14 \%$ and $20 \%$ of all collaborative decisions in the Project Definition phase. After this period we have organised several semi-open interviews. Each interview was 1 to $1.5 \mathrm{~h}$ long.

For each collaborative decision, a context is defined constituted of decision-making related context, project related context and enterprise related context. In order to illustrate the impact of the context related data, we propose to illustrate how the context data changed a given decision. For each related context a specific collaborative decision is discussed. 
EXAMPLE FOR DECISION MAKING CONTEXT: Concept choice decision (Design Style Collaborative Decision Making CDM Process)

The decision concerning the vehicle design does not imply the same risks for design department and for vehicle architecture department. If a design department proposes more "sport"-like line (aggressive lines and very close to the ground), for vehicle architecture department just a question of windshield concerns the risks of production techniques: is it possible to produce a windshield with a high resistance and with the high inclination angle? In previous cases, the decision would be made solely based on the attractiveness of the vehicle design. For this decision, in the decision-context a vehicle architecture department is defining a list of risks related to this decision (risks related to the manufacturing process or risks related to technical feasibility). This data is shared during the decision, and the expert evaluation of associated risks has a strong impact on the concepts that will be further investigated.

EXAMPLE FOR PROJECT RELATED CONTEXT: Innovation integration decision (Innovation CDM Process)

Innovation integration decision aims at defining a set of innovations that are to be integrated in the vehicle design. Market segment data (Project related context) is crucial for this decision. In this case, the project team will have details on a given market segment and vehicle that are considered as leaders in this segment. If the vehicle design concerns the large market segment with a considerable impact on the company brand, then this decision is critical and might involve strategy development department thus changing the collaborative decision level. Decision makers need to evaluate potential innovation and possible impact propagations on the vehicle design. If the vehicle project concerns a market niche that is not identified for the time being, then this decision is not as important. The decision will include smaller innovation panel (maybe one or two innovations). However, the Time-To-Market could be reduced in order to gain competitive advantage as being the first manufacturer to satisfy these needs.

EXAMPLE FOR ENTERPRISE RELATED CONTEXT: Selection of suppliers (Purchase CDM Process) 
Supplier selection is an important decision because it will impact overall project success depending on supplier performance and reliability. In the case of this decision, enterprise related context has a major influence. For instance, if one the objectives concerned competitive advantage that is related to cost and thus the overall company purchasing strategy, then some of the data in the process enhancement could be related to the reorganisation of the purchasing process. The decision without the process enhancement would concern the list of supplier panel and their performances; and would concern only the choice amongst proposed suppliers. If the objectives of the project concern also the purchasing process, then the decision would need to consider other ongoing projects and would impact overall purchasing process impacting purchase process time lines and the definition of suppliers' capabilities.

\section{Discussion}

The utility of context related data was discussed in the Implementation and Validation phase of our research study. As highlighted previously, a test bed consisting of $25 \%$ of launched projects has been defined to test the tool developed for the collaborative decision-making support. This phase covered some 10 to 15 decision per project, constituting up to $20 \%$ of decisions covered in the Project Definition phase. The semi-open interviews were organised with project planners and Project Management Office to determine the relevance of the gathered data and eventual lacking in tool development. Three types of project roles were taken into account (see Figure 7). The roles were decided with the Project Management Office because they were considered to be direct users of this kind of information during the design project.

\begin{tabular}{l|ll}
\hline & Role & Previous Experience \\
\hline D1 & $\begin{array}{l}\text { Project Management } \\
\text { Office Manager }\end{array}$ & Vehicle project director, Project planning, Architecture design \\
D2 & $\begin{array}{l}\text { Design engineer: } \\
\text { vehicle design support }\end{array}$ & $\begin{array}{l}\text { Innovation management, Project planning, Engine design, } \\
\text { methodology }\end{array}$ \\
D3 & Project planner & Project Planning, Design support \\
\hline
\end{tabular}
Figure 7. Project roles that were selected for the semi-open interviews for the validation phase.

Several questions were asked concerning the context modelling and its contribution in the collaborative decision-making process as well as vehicle design. Questions were open-ended and mostly we wanted to see if the context data contributed to the conceptual design convergence and 
conflict apparition reduction. The questions concerned the relevance of the data to support the design solution space definition, the quality and accuracy of gathered data, the importance of this data during the project, the facility of finding the adequate data and the difficulty/facility of maintenance. In all projects the conclusion was that context modelling: (1) helps to prevent conflict apparition; (2) help to elicit hypothesis and to reduce the solution space in the CDM process; and (3) can be an interesting way to support knowledge capitalization concerning the NPD process. Context modelling prevent conflict apparition because it explicit the constraints between different departments, like in the case of concept choice. Taking into these constraints opens us the possibility for further discussion and negotiation. It can also support hypothesis elicitation because some of underlying hypothesis that were maybe not clear have been captured (for example the objectives related to process enhancement or decision priorities with regard to market segmentation and innovation panel). Project members also underlined that they though that context modelling supports capitalization process in the vehicle design. The project team has further gathered context related data to prepare the decision or simply after the decision for the traceability. This data is captured and store in the collaborative decision view of the tool and is considered to be useful for future projects.

\section{CONCLUSIONS}

Context definition and modelling has been a growing issue in cognitive sciences as well as engineering (Brézillon, 1999a; Longueville \& Gardoni, 2003). Brézillon (Brézillon, 1999a) has pointed out the difference in approaches in artificial intelligence and engineering, though from the author's point of view this difference is due to different roles that context plays in these domains. Among the different approaches that exists for context modelling we have chosen to present in this paper the ones that are important for modelling the context as a knowledge and rules thus helping the decision making process.

In this paper, we propose the definition of three embedded contexts as a part of the Environment view of our collaborative decision making model: decision, project and enterprise context. We define the context as influencing factors or constraints that are essential in focusing the problem solving process and that are to be defined in a common effort with all actors participating in this process. This research 
work concerns 7 vehicle development projects in a French automotive company where the proposed collaborative decision making model is implemented.

The implementation of our proposition concerns only one company. Although we consider this test bed to be relevant because the sample of chosen projects represents over $40 \%$ of ongoing projects and $20 \%$ of launched projects, we consider that there is more testing to be done. We think that it would be interesting to explore the possibility of generalization of influencing factors across companies and industry fields. For example, in our case the project types influencing factors can be considered as to be particular to the automotive industry. Further exploration would be necessary to determine if it is possible to generalize these factors for the whole industry branches or generalizing factors as to relate the consideration of characteristics of different project types (complex systems, innovation development projects, distributed projects).

\section{REFERENCES}

Akman, V., \& Surav, M. (1996). Steps toward Formalizing Context. AI Magazine 17(3), 533-552.

Aldag, R.J., \& Fuller, S.R. (1993). Beyond Fiasco: A Reappraisal of the Groupthink Phenomenon and a New Model of Group Decision Processes. Psychological Bulletin 113(3), 533-552.

Barwise, J., \& Perry, J. (1983). Situation and Attitudes. MIT Press, Cambridge, MA.

Blessing, L.T.M., \& Chakrabarti, A. (2009). DRM, a Design Research Methodology. Springer.

Brézillon, P. (1999a). Context in Artificial Intelligence: A survey. In, pp. 1-28. LIP 6, University Paris 6, Paris.

Brézillon, P. (1999b). Context in Artificial Intelligence: Key elements. In, pp. 1-27. LIP 6, University Paris 6, Paris.

Brézillon, P., \& Pomerol, J. (1996). User acceptance of interactive systems: Lessons from knowledge-based and decision support. International Journal of Failure \& Lessons Learned in Information Techology Management $1(1), 67-75$.

Brézillon, P., \& Zaraté, P. (2004). Group Decision Making: A Context oriented view. IFIP WG8.3 International Conference on Decision Support Systems DSS2004, (R. Meredith, G.S., D. Arnott, S. Carlsson, Ed.), pp. 123133. Prato, Italy.

Culley, S.J., \& McMahon, C.A. (2006). The Issues for Product Development of Handling Long Life Design Information. 6th IPD workwhop. Magdeburg. 
Devlin, K. (1995). Logic and Information. Cambridge University Press.

Edmonds, B. (1999). The Pragmatic Roots of Context. CONTEXT'99. Trento,Italy.

Esser, J.K. (1998). Alive and Well after 25 Years: A Review of Groupthink Research. Organizational Behavior and Human Decision Processes 73(2-3), 116-141.

Frege, G. (1985). On sense and meaning. In The Phylosophy of Language, pp. 212-220. Martinich A.P.

Fruchter, R., Saxena, K., Breidenthal, M., \& Demian, P. (2007). Collaborative design exploration in an interactive workspace. AI EDAM: Artificial Intelligence for Engineering Design, Analysis, and Manufacturing 21(03), 279-293.

Giunchiglia, E., Traverso, P., \& Giunchiglia, F. (1992). Multi-context systems as a specification framework for complex reasoning systems. ECAI'93 Workshop on Formal Specification Methods for Complex Reasoning Systems. Vienna, Austria.

Gonzalez, A.J., Tsuruta, S., Sakurai, Y., Nguyen, J., Takada, K., \& Uchida, K. (2011). Using contexts to supervise a collaborative process. Artificial Intelligence for Engineering Design, Analysis and Manufacturing 25(01), 25-40.

Guha, R. (1995). Contexts: A Formalization and Some Applications. Stanford University.

Hasher, L., \& Zack, R.T. (1984). Automatic processing of fundametal information: the case of frequency of occurence. American Psychologist 39, 1372-1388.

Henricksen, K., Indulska, J., \& Rakotonirainy, A. (2002). Modeling Context Information in Pervasive Computing Systems. Lecture Notes in Computer Science 2414/2002, 79-117.

Henricksen, K., Indulska, J., \& Rakotonirainy, A. (2003). Generating Context Management Infrastructure from High-Level Context Models. 4th International Conference on Mobile Data Management (MDM 2003), pp. 1-6. Melbourne, Australia.

Janis, I. (1971). Groupthink. Psychology today, 43-46.

Jankovic, M. (2006). Collaborative decision making in new product development. Application to the car industry. In Industrial Engineering Laboratory. Ecole Centrale Paris, Paris.

Jankovic, M., Stal Le Cardinal, J., \& Bocquet, J.-C. (2010). Collaborative Decision in Design Project Management. A Particular Focus on Automotive Industry. Journal of Decision Systems 9(1), 93-117.

Jankovic, M., \& Zaraté, P. (2011). Discrepancies and Analogies in Artificial Intelligence and Engineering Design Approaches in Adressing the Collaborative Decision-Making. International Journal of Decision Support System Technology (IJDSST) 3(2), 1-14.

Jankovic, M., Zaraté, P., Bocquet, J.-C., \& Stal Le Cardinal, J. (2009). Collaborative Decision Making: Complementary Developments of a Model and an Architecture as a Tool Support. International Journal of Decision Support System Technology (IJDSST) 1(1), 35-45. 
Leech, G. (1981). Semantics : the study of meaning Harmondsworth Middlesex England, New York, USA.

Longueville, B. (2003). Capitalisation des processus des décisions dans les projets d'innovation: Application à l'automobile. In Industrial Engineering Laboratory. Ecole Centrale Paris, Paris.

Longueville, B., \& Gardoni, M. (2003). A Survey of Context Modelling: Approaches, Theories and Use for Engineering Design Researches. ICED 03: 14th International Conference on Engineering Design. Stockholm, Sweden.

McCarthy, J. (1993). Notes on formalizing context. 13th International Joint Conference on Artificial Intelligence, pp. 555-560. San Mateo, CA; USA.

Ozturk, P., \& Aamodt, A. (1998). A Context Model for Knowledge-intensive Case-based reasoning. International Journal of Human-Computer Studies 48(3), 331-335.

Pomerol, J.C., \& Brezillon, P. (2001). About some relationships between knowledge and context. In Modeling and Using Context, Proceedings, Vol. 2116, pp. 461-464.

Pomerol, J.C., \& Brezillon, P. (2003). Context proceduralization in decision making. In Modeling and Using Context, Proceedings, Vol. 2680, pp. 491-498.

Schilit, B., Adams, N., \& Want, R. (1994). Context-aware computing applications. IEEE Workshop on Mobile Computing Systems and Applications. Santa Cruz, California; USA.

Schmidt, A., Beigl, M., \& Gellersen, H.-W. (1999). There is more to context than location. Computers \&amp; Graphics 23(6), 893-901.

Strang, T., \& Linnhoff-Popien, C. (2004). A context modelling survey. Workshop on Advanced Context Modelling, Reasoning and Management as part of UbiComp.

Surav, M., \& Akman, V. (1994). Context and Situations. In, pp. 1-50. Bilkent University.

Tiberghian, G. (1986). Context and cognition: Introduction. European bulletin of cognitive psycholog 6(2), 105119. 